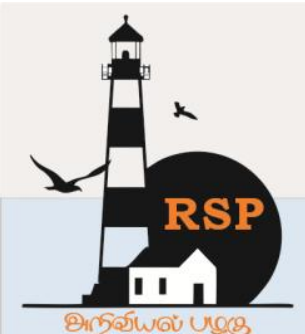

INTERNATIONAL RESEARCH JOURNAL ON ADVANCED SCIENCE HUB

ISSN : $2582-4376$
Open Access

RSP SCIENCE HUB

(The Hub of Research Ideas)

Available online at www.rspsciencehub.com

Special Issue of First International Conference on Engineering, Science, and Technology (ICEST 2021)

\title{
A Study of Aggression among Adolescents
}

Sona Thakur ${ }^{1}$, Dr Kuldip Kaur Grewal' .

${ }^{1}$ Research Scholar, CT University, Ludhiana, Punjab, India.

${ }^{2}$ Professor, Department of Education, School of Humanities and Physical Education, CT University, Ludhiana, Punjab, India.

sonaathakur@gmail.com ${ }^{1}$

\begin{abstract}
The present paper aims to study prevalence of aggression among adolescents. A descriptive study was conducted to explore the relationship between aggression and family environment among adolescents. A sample consisting of 200 adolescents was taken from the three districts of Punjab state namely Ludhiana, Sangrur and Hoshiarpur. Data was collected with the help of Aggression Scale by Dr. G.P.Mathur and Dr. Raj Kumari Bhatnagar (2012) and Family Environment Scale by Dr. Harpreet Bhatia and Dr. N.K. Chadha (2015) .Subsequently data was subjected to statistical analysis. Results clearly indicated a significant relationship between overall aggression and family environment of adolescent students.

Keywords: Aggression, family environment, Adolescents, distict.
\end{abstract}

\section{Introduction}

Among all developmental stages, adolescence stage is considered as a very crucial stage that needs to be studied. If the behavior of the adolescents is properly modified and their energy is properly channelized, they can prove to be a boon for the society. India is a developing country and in the present scenario, our youth is indulging in many anti-social activities like- physical assault, acid attack, killing, threatening, shooting, committing suicide, terrorism etc. and aggression is ultimately responsible for all these activities, which is not a good sign for the society.

In our daily life, we observe the media reports of physical assault, acid attacks, violent threats, unexpected aggression and so many other kinds of attacks that are common in the headlines. According to Carney (2000) "Through the media, we learn of an adolescent who commits some horrifically violent act, another adolescent, for no apparent reasons or critical incident, seemingly erupts and seriously injures or kills someone.
"Govender and Killian (2001) exposed the reports of $73 \%$ learners witnessing school violence, $10 \%$ reported that being a member of a group they had killed an individual, while $4 \%$ indicated that they had killed an individual without being a member of that group. From these studies, it seems that we are living in a world that is becoming more violent day by day.

In India, majority of the young children, due to undesired and unfavorable atmosphere at home, school and society are the victims of various behavioral problems such as hyperactivity, aggressiveness, violation, non-compliance, social withdrawal, disruptive behavior etc. Among these behavioral problems, aggressive behavior is the most troublesome problem and is of key concern not only for parents and teachers but also for the entire society.

\subsection{Aggression}

In children and adolescents, violence is the most 


\section{www.rspsciencehub.com}

critical psycho-pathological risk factor and can impact their social, psychological and physical wellbeing. In social psychology, aggression refers to behaviours formed to hurt another person. The concept of aggression falls into two categories: instrumental aggression and hostile aggression. While instrumental aggression is used to accomplish an objective or purpose, hostile aggression is intended to hurt others and involves two types of overt aggression (physical and verbal) and social aggression.Physical violence refers to hurting someone deliberately to cause him discomfort, such as punching, pushing, throwing things, etc. The use of offensive language such as shouting and screaming that causes a person's hurtful feelings and credit and lowers the value of a person is called verbal aggression.Social violence refers to behaviour aimed at undermining the social status and friendships of others. Some forms of social violence include heavy silence and negligence. Among children and teenagers, violence is prevalent.

We mean we are educated and civilized and belong to one of the world's great nations. We are proud of our high traditions, glorious culture and heritage, and we are proud of our forefathers' contributions and sacrifices to the country. However, at the same time, we feel ashamed of the dangerous increase in our current generation's offensive and violent actions in the world.Although the degree of violence and aggression varies from place to place, from society to and from country to country (Mohanty 2005).

Aggression is aggressive and disruptive conduct that is deliberately directed towards other persons or the community in an anti-social sense. Aggression can either be directed inwards by selfmutation or suicidal tendencies or directed outwardly at other people. Aggression is an action that is intended to harm someone. Aggression can be covert and not as detectable. This covert style of aggression can also be confrontational and non confrontational depending on the type of aggression. Typically, aggression is predominately understood by many as direct physical or verbal attacks instead of these more covert methods. A sense of vulnerability, low self-confidence and hostility is created by the lack of caring, welcoming and affectionate behaviour of parents.
Volume 03 Issue $01 S$ January 2021

According to Johnson (1972) aggression is "physical or verbal behaviour that is intended to hurt someone". Bhagi and Sharma (1992) views that aggression is, "injurious and destructive behaviour. Coi and Dogde(2000) defined as "any behaviour intended to harm an individual who is motivated to avoid being harmed."

It can be concluded at that aggression is a behaviour, which indulges an individual to hurt others either verbally or physically for his own sake to satisfy his desires. By the different views of researchers, it can also be said that aggressive behaviour includes robbery, kidnapping, terrorism, irritability, quarrelling, hitting, kicking, rudeness, jealousy, stabbing, shooting, snatching, scratching etc. It is, therefore, an omnibus term with different meanings related to different kinds of behaviour held together under a general term -aggression.

\subsection{Family Environment}

The family is human society's oldest, most basic and fundamental entity. It is a social institution that conveys our social heritage through it. Most of what we used to call heritage is simply the family's influence. Traditionally, the family is seen as the underlying pillar of society. Families can usually be seen as a group of individuals with biological, emotional or legal links to each other. It is well known that it is the most significant element that influences our thinking and attitudes by far.

Tiwari (1998) states that family environment is, "the most important agent that influences the child's relationship with family."According to Clare (2003) "family we mean a system of relationship existing between parents and children." "The family constitutes an interpersonal social system held together by strong bond of attachment, affection, care and yet exercises control, approval and discipline on each other's actions ", (Harvey \& Byrd, 2000; Parke \& Buriel, 1998).

Family environment is the first and perhaps the most evolving context for growth. It consists family members along with their attitudes, personality, behaviour, inter relationship etc. Family environment bearing healthy and high quality characteristics affects the development of the child in many ways like ego concept of the child and his/her emotional and social 
development. Social status of the parents, the residence, relations within the family, the number of siblings and the relations among the siblings determine the characteristics of the family environment. Compared with normative families, the families of youth with behavioural problems or conduct disorders tend to be low in cohesion, expressiveness, independence, organization and active recreational orientations. They are found high in conflict and control (Moos \& Moos, 1994).

\section{Review of Related Literature}

Many studies have been conducted to study the relationship aggression and family environment among adolescents. Rana and Malhotra (2005) demonstrated that family environment affected aggressive behaviour. Gender differences, as expected showed that boys scored higher than girls did on physical, verbal and indirect aggression. Kaur and Niwas (2015) found average aggression level among secondary school students. 25\% of secondary school students show high aggression, $64 \%$ students show average aggression and $11 \%$ students show low aggression. A positive correlation was found between aggression and most of the dimensions of family environment.

Kumar and Thakur (2016) in their study found a significant negative relationship between the aggression and five dimensions of family environment (i.e. cohesion, conflict, acceptance and caring, independence and active recreational orientation).Jain (2017) revealed that there were significant mean differences among aggression level of adolescents of cohesive family environment and adolescents of poor family environment. When both the groups of adolescents were compared on overall ten measures of family environment scale (viz., cohesion, expressiveness, conflict, independence, achievement orientation, intellectual orientation, active recreational orientation, \&amp; moral religious emphasis) it was found that high aggression level adolescents come from poor family environment. Sharma (2019) a significant negative correlation between family environment and aggression. Significant differences were found between adolescents of congenial and average, average and poor, congenial and poor family environments in their aggression. Adolescents of congenial family environment were less aggressive.

\subsection{Objectives of the Study}

1.To study aggression among adolescents.

2. To study the relationship between aggression and family environment among adolescents.

\subsection{Hypothesis of the study}

There exists no significant relationship between aggression and family environment among adolescents.

\section{Method and Materials}

The purpose of this research was to study adolescent aggression in relation to the family environment. In order to achieve the objectives of the analysis, the descriptive survey approach was used to perform the current research, and statistical methods were used to analyse and interpret the findings. The correlation coefficient was employed to determine the relationship between aggression and the family environment. 200 students (100 boys and 100 girls) were selected for the current research from various government schools located in the districts of Ludhiana, Sangrur and Hoshiarpur. Data was gathered by using Dr. G. P. Mathur's and Dr. Raj Kumari Bhatnagar's (2012) Aggression Scale and Dr. Harpreet Bhatia's and Dr. N. K. Chadha's (2015) Family Environment Scale.

\subsection{Delimitations of the Study}

1. The study was delimited to $9^{\text {th }}$ class adolescents only.

2. The study was delimited only to Government schools of the state of Punjab.

\section{Results and Discussion}

Pearson's Product Moment correlation methodology was used as the present study is intended to find out the relationship between aggression and family environment among adolescent students.

Table 1. shows that the coefficient of correlation between aggression and cohesion dimension of family environment among adolescents is- 0.19 which is negative and significant at .01 level of confidence which shows that there exists a significant negative relationship between aggression and cohesion dimension of family environment of adolescents. This indicates that the adolescents having less cohesive family environment in terms of commitment, help and support will be more aggressive whereas 
adolescents having more cohesive family environment will be less aggressive. The coefficient of correlation between aggression and expressiveness dimension of family environment among adolescents is -0.21 that is negative and significant at .01 level of confidence that shows that there exists a significant negative relationship between aggression and expressiveness dimension of family environment of adolescents. This indicates that the extent to which adolescents are encouraged to act openly and express their feelings and thoughts directly will develop aggressive feelings among them, more freedom less aggression.

Table.1. Coefficient of correlation between aggression and family environment $(\mathrm{N}=200)$

\begin{tabular}{|l|c|}
\hline \multicolumn{2}{|l|}{$\begin{array}{l}\text { Coefficient of correlation between aggression and family environment } \\
\mathbf{N}=\mathbf{2 0 0})\end{array}$} \\
\cline { 2 - 3 } Dimensions of Family Environment & Coefficient of Correlation (r) \\
\hline Cohesion & $-0.19^{* *}$ \\
\hline Expressiveness & $-0.21^{* *}$ \\
\hline Conflict & $0.31^{* *}$ \\
\hline Acceptance and Caring & $-0.23^{* *}$ \\
\hline Independence & -0.16 \\
\hline Active Recreational Orientation & $-0.25^{* *}$ \\
\hline Organization & -0.07 \\
\hline Control & -0.08 \\
\hline
\end{tabular}

** Significant at 0.01 level

The coefficient of correlation between aggression and conflict dimension of family environment among adolescents is 0.31 that is positive and significant at .01 level of confidence that shows that there exists a significant positive relationship between aggression and conflict dimension of family environment of adolescents. This indicates that the adolescents having more conflict in family environment will be more aggressive whereas the adolescents having less conflict in the family environment will be less aggressive. The coefficient of correlation between aggression and acceptance and caring dimension of family environment among adolescents is -0.23 that is negative and significant at .01 level of confidence that shows that there exists a significant relationship between aggression and acceptance and caring dimension of family environment of adolescents. This indicates that if adolescents are not accepted and cared in the family they will show aggressive behavior.

The coefficient of correlation between aggression and independence dimension of family environment among adolescents is -0.16 that is negative and non-significant at .01 level of confidence that shows that there exists no significant relationship between aggression and independence dimension of family environment of adolescents. The coefficient of correlation between aggression and active recreational orientation dimension of family environment among adolescents is- 0.25 that is negative and significant at .01 level of confidence that shows that there exists a significant relationship between aggression and active recreational orientation dimension of family environment of adolescents. This implies that the adolescents having less active participation in social and recreational activities in the family environment will show high levels of aggression. 


\section{www.rspsciencehub.com}

The coefficient of correlation between aggression and organization dimension of family environment among adolescents is 0.07 that is not significant at .01 level of confidence that shows that there exists no significant relationship between aggression and organization dimension of family environment of adolescents. The coefficient of correlation between aggression and control dimension of family environment of adolescents is- 0.08 that is not significant at .01 level of confidence that shows that there exists no significant relationship between aggression and control dimension of family environment of adolescents.

Results of the present shows that there exists a significant relationship between aggression and various dimensions of family environment like cohesion, expressiveness, conflict, acceptance and caring, independence and active recreational orientation. Therefore hypothesis, stating that 'There will be no significant relationship between aggression and family environment among adolescents stands rejected." These results are in line with the findings of Sharma and Sangwan (2016), who agree that aggression has a positive and significant correlation with the dimension of conflict, while cohesion, expressiveness, acceptance and caring, active recreational organization, freedom, organization and control dimensions are negatively and significantly correlated.

\section{Conclusion}

Theories of social learning indicate that through environmental interactions, violent behavior is learned and retained. Overnight, aggression does not develop, and is mostly homebred. Experts attribute aggression to a combination of factors that increase media and internet exposure to abuse, lack of parental control, tension with repetition and use of foul language at home, lack of child-parent contact, faulty discipline, school performance burden, increasing drug addiction, increased junk food consumption and sedentary lifestyle (Broota,2008). It can therefore be inferred that the family environment applies to all kinds of moral and ethical principles and the emotional, social and intellectual atmosphere set up by members of the family for an individual's healthy growth. The richness of the family setting is reflected in the
Volume 03 Issue 01S January 2021

child's attitude. In the moulding of the child's personality, the family atmosphere has been recognized as critical.

\section{References}

[1].Bhagi. M \& Sharma, S. (1992). Encyclopaedic Dictionary of Psychology(Vol. 1) Animal Publisher, New Delhi.

[2].Bhatia, H. \& Chadha, N.k., Family Environment Scale. National Psychological Corporation, Agra. (2015).

[3].Broota, A. (2008) Hot Cross kids: A growing number of angry urban children are capable of violence Pp 22-26 cited by Sharma ,G. The week, Jan, 2008.

[4].Carney, J.V. (2000).Bullied to death. School of Psychology International, 21(2), 213- 223.

[5].Clare, Foundations of Educations: thought and practice. Surya Publication, Meerut. (2003).

[6].Coi , J.D. \& Dodge, K.A (2000). Aggression and Anti Social Behaviour in W. Damon (Series ed) and N. Eisenberg (vol.ed); Handbook of child Psychology, Social Emotional and Personality Development, Wiley, New York.

[7]. Govender, K., \& Killian, B. J. (2001). The psychological effects of chronic violence on children living in South African townships. South African Journal of Psychology. 31(2), $1-24$.

[8].Harvey, M., \& Byrd, M. (2000). Relationship between adolescents' attachment styles and family functioning. Adolescence, 35(138), 345-356.

[9].Jain,J.(2017).Family environment and aggression in adolescents: A Correlational Study. Indian Journal of Health and Wellbeing.8(7),598-601.

[10].Johanson, R. , Aggression in Man and Animal, Philadelphia: Saunders.(1972).

[11].Kaur,D. \& Niwas , R. (2015). Aggressive behaviour of secondary school students in relation to their family environment. Scholarly 
Research Journal for Interdisciplinary Studies,4(27),4341-4345

[12].Kumar, A \& Thakur, S. (2016) Aggression Among Senior Secondary Students In Relation To Family Environment. International Journal of Recent Scientific Research. 7 (1), 83028305 .

[13].Mathur G.P and Bhatnagar R.K. , Manual for Aggression Scale. Rakhi Prakashan, Agra.(2012).

[14].Mohanty, G, Psychology of aggression, Violence and Crime. New Delhi: Kalyani Publishers.(2005).

[15]. Moos, R.H. \& Moos, B.S , Family Environment Scale Manual (2nd ed.) Palo Alto, CA: Consulting Psychologists Press.(1994).

[16].Parke, R. D., \& Buriel, R. B. (1998). Socialization in the family: Ethnic and ecological perspectives. In N. Eisenberg (Ed.), Handbook of child psychology (5th Ed.). New York: Wiley

[17].Rana ,M. \& Malhotra , D. (2005).Family environment as a predictor of aggressive behaviour. Studia Psychologica, 47(1),61-74.

[18].Sharma, D. \& Sangwan, S. (2016). Impact of family environment on adolescent aggression. Advance research journalofsocial science. 7(2), 225-229.

[19].Sharma,P.(2019). Aggression in relation to family environment of adolescents belonging to urban and rural areas. Journal of Emerging Technologies and Innovative Research. 6(1),212-217.

[20].Tiwari (1998). Religiosity as a co-relate of ego identity of adolescent from joint and nuclear families. Indian Journal Psychometric and Education. 21(5), 45-46. 